Article

\title{
First Flush Characteristics in Separate Sewer Stormwater and Implications for Treatment
}

\author{
Sara Egemose * $\mathbb{C}$, Anne B. Petersen, Melanie J. Sønderup and Mogens R. Flindt \\ Department of Biology, University of Southern Denmark, DK-5230 Odense M, Denmark; \\ abpfole@hotmail.com (A.B.P.); msp@niras.dk (M.J.S.); mrf@biology.sdu.dk (M.R.F.) \\ * Correspondence: saege@biology.sdu.dk; Tel.: +45-6550-7988
}

Received: 30 May 2020; Accepted: 18 June 2020; Published: 22 June 2020

check for updates

\begin{abstract}
The characteristics of stormwater need focus due to climate change. Paved areas and recipients receiving more stormwater have an enhanced need for treatment before discharge to remove suspended solids, nutrients and xenobiotics. To handle and treat stormwater efficiently, knowledge concerning first flush patterns is crucial. Therefore, we have studied 12 entire rain events and correlated water volume, suspended solids, and dissolved and particulate phosphorus to catchment characteristics and precipitation characteristics. We have mainly studied smaller rain events (average $12.6 \mathrm{~mm}$ ), as nearly $90 \%$ of the events in the studied catchment are $<10 \mathrm{~mm}$. We revealed first flush tendencies in $50 \%$ of the rain events, concerning both suspended solids and phosphorus. We also found significant correlations between catchment size and discharged masses, and most importantly between precipitation patterns and discharged mass per volume. A long dry period and low amount of rain during the previous event, as well as high rain intensity, gives a high chance of first flush. We conclude that stormwater treatment should focus on the initial part of the event, especially in areas with a lack of space and/or economy to handle and treat the entire event.
\end{abstract}

Keywords: urban runoff; climate adaptation; pollution; retention

\section{Introduction}

Climate change is among the many other effects causing more extreme weather, including cloud bursts, storms and droughts [1,2]. For the northern part of Europe, an increased amount of precipitation with more and heavier rain events is expected [3]. As an example, it is predicted that the number of 10 year events in Denmark will increase by $30 \%$ within the next 100 years [4].

Stormwater runoff from separate sewers is most often either discharged directly into the recipient or discharged after retention, e.g., in a wet stormwater pond [5]. Especially the first stormwater discharged will often have a larger content of particles and dissolved substances compared to the remaining part, as the first discharge contains all the accumulated particulate material from surfaces and the pipe systems [6,7]. This phenomenon is referred to as 'first flush', and is defined as a disproportionally high load of either concentration or mass in the first stormwater load during a rain event $[7,8]$. First flush depends on the dry period before the actual event, the intensity and duration of the rain event, the catchment type, and the transport distance of the discharge before the outlet (pipe length) [9]. Historically, different methods have been used to describe first flush events.

A commonly used method is to express the percentage of mass transported along with a certain percentage of the volume [9], presented as normalized accumulated mass ( $\mathrm{L}^{\prime}$ ) for each time as a function of normalized accumulated volume $\left(\mathrm{V}^{\prime}\right)$ at each time [9]. A $45^{\circ}$ bisector will then represent a proportional transport of mass and volume, see example in Figure 1. If the curve is above the bisector, a relatively larger mass is transported in the discharge compared to the transported volume, whereas 
the opposite is the case if the curve is below the bisector; in that case, the runoff is diluted. So, if first flush is occurring, the curve will be above the $45^{\circ}$ line $[9,10]$.

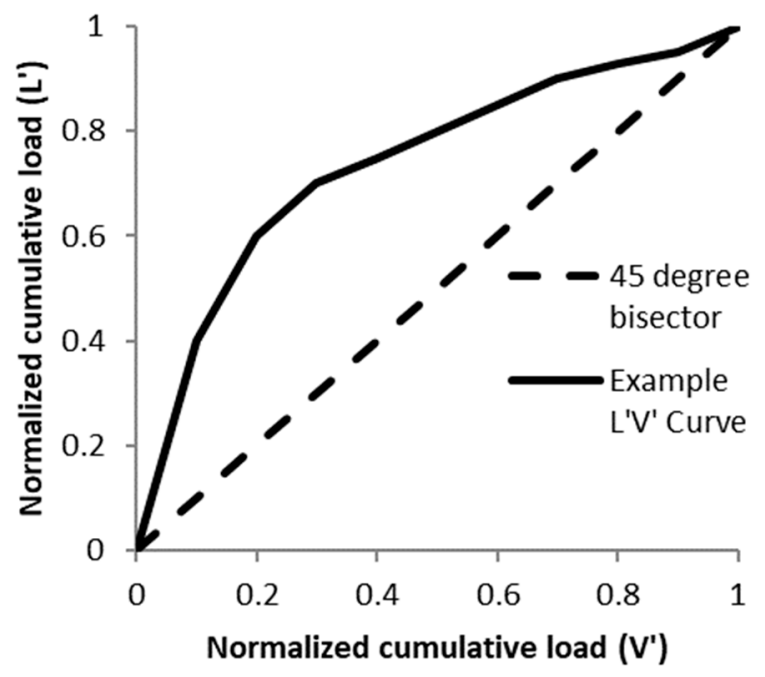

Figure 1. Schematic $L^{\prime} / V^{\prime}$ curve-redrawn after [9]. $L^{\prime}$ is the mass load and $V^{\prime}$ is the volume. Both are expressed as normalized accumulated values.

The numerical definition of the first flush varies. Some have suggested that first flush is characterized by an $80 \%$ mass transport during the first $30 \%$ of the volume-a $30 / 80$ first flush $[10,11]$. Others have argued for an even stronger characterization, where $80 \%$ of the mass should be transported during the first $20 \%$ of the volume-a 20/80 first flush [7]. Finally, some studies have suggested a less strict definition with first flush at $20 / 40$ or $25 / 50$ as first volume/mass [9]. In general, first flush is most common in smaller catchments ( $<10$ ha) [11].

A well-known method to store stormwater and avoid hydraulic effects on the recipient, as well as to remove primarily particulate substances, is wet stormwater ponds [12,13]. In Denmark, wet ponds are often designed with a controlled outlet intensity of $1-2 \mathrm{~L} / \mathrm{s} / \mathrm{ha}$ catchment, a permanent wet volume of $150-250 \mathrm{~m}^{3} /$ reduced hectare and a storage volume, if properly designed [5]. The reduced area is the impermeable proportion of the catchment. Many of the wet stormwater ponds are designed with an overflow facility placed near the pond outlet, which is activated if the pond's storage capacity is exceeded. The result is that it will most likely be the discharge that entered the pond first that will be discharged first during overflow. Put another way, the first flush holding the most polluted water might be discharged through the overflow if the storage capacity of the pond is exceeded, and the cleaner water coming after the first flush is kept in the pond and treated. That is an undesirable, and environmentally and economically inefficient way of handling stormwater.

Therefore, a greater knowledge of the first flush phenomenon will support the knowledge platform so that the design of stormwater ponds can be optimized and make it possible to retain and treat first flush, without making the ponds inappropriately big. Barbosa and Hvitved-Jacobsen have suggested that the treatment efficiency could be enhanced by placing the overflow facility at the inlet instead, so that the more diluted, cleaner stormwater coming after first flush is bypassed instead of the most polluted first flush [6]. This will not change the hydraulic load, but it will entail that if overflow occurs, it will be the cleanest water that overflows. A model study in progress made on Danish ponds has revealed that this change in design can effectively increase the treatment efficiency.

The important question is what proportion of the first flush should be kept in the stormwater pond and treated. To provide more information about that, we have examined the runoff from 12 rain events in three different catchments with varying intensity, duration and dry weather periods since last rain event. The aims were (1) to characterize to what extent first flush was observed with respect to 
suspended solid (SS), dissolved phosphorus (DP) and particulate phosphorus (PP), and (2) to evaluate which catchment and precipitation patterns the first flush was dependent on.

\section{Materials and Methods}

In the period 2012-2017, we examined the runoff from 12 different rain events at 3 different stations (Table 1). All stations are in the southern part of Denmark, and were named Graasten 1-6, Aabenraa 1-2 and Padborg 1-4, respectively; first the city name, then the rain event number. In Graasten, the catchment is a mixed urban area with roads and houses. The total catchment area is $4.2 \mathrm{ha}$, and the reduced catchment is $1.5 \mathrm{ha}$. In Aabenraa, the catchment area consists of light industry and it is nearly 5 times larger (23.1 ha, 5.8 red. ha) compared to the Graasten area. In between the two is Padborg, with a total catchment area of 15.5 ha and 10.1 red. ha. In contrast to the two others, this catchment only consists of roads and parking lots. The maximum pipe length, equal to the maximum length that the water is transported before discharge, varies from $600-1400 \mathrm{~m}$. The investigated rain events covered a wide range of rain amounts, 6-24.4 mm (median 12.3, average 12.6), and the events lasted 6-52 $\mathrm{h}$ (median 13, average 22). The intensity of the rain ranged $0.2-2 \mathrm{~mm} /$ hour, along with the number of days since last rain event (1-8 days). Finally, the amount of rain during the previous event varied 1.4-18.6 $\mathrm{mm}$. In Graasten, all precipitation data were measured by an on-site Netatmo rain measure with tipping function, measuring the precipitation with a precision of $0.2 \mathrm{~mm}$. In Aabenraa and Padborg, a Global Water RG200 Rain Gauge, 6 inches (Tipping bucket), was used, also with a precision of $0.2 \mathrm{~mm}$.

Table 1. Descriptive data of the 12 studied outlets, including catchment characteristics and precipitation patterns.

\begin{tabular}{|c|c|c|c|c|c|c|c|c|c|}
\hline \multicolumn{5}{|c|}{ Catchment } & \multicolumn{5}{|c|}{ Precipitation } \\
\hline Location & Date & $\begin{array}{c}\text { Catchment } \\
\text { Type }\end{array}$ & $\begin{array}{c}\text { Catchment } \\
\text { Size } \\
\text { (Total/Red ha) }\end{array}$ & $\begin{array}{c}\text { Max } \\
\text { Distance } \\
\text { Catchment } \\
\text { (m) }\end{array}$ & Rain (mm) & Duration (h) & $\begin{array}{c}\text { Mean } \\
\text { Intensity } \\
(\mathrm{mm} / \mathrm{h})\end{array}$ & $\begin{array}{c}\text { Dry } \\
\text { Period } \\
\text { (Days) }\end{array}$ & $\begin{array}{c}\text { Rain in } \\
\text { Last } \\
\text { Event } \\
(\mathrm{mm})\end{array}$ \\
\hline Graasten 1 & $11 / 01 / 17$ & Urban & $4.2 / 1.5$ & 600 & 8.9 & 5.6 & 1.6 & 1 & 1.0 \\
\hline Graasten 2 & $22 / 02 / 17$ & Urban & $4.2 / 1.5$ & 600 & 13.7 & 7.0 & 2.0 & 2 & 4.5 \\
\hline Graasten 3 & $23 / 02 / 17$ & Urban & $4.2 / 1.5$ & 600 & 12 & 6.6 & 1.8 & 1 & 13.9 \\
\hline Graasten 4 & $17-18 / 03 / 17$ & Urban & $4.2 / 1.5$ & 600 & 15.9 & 19.4 & 0.8 & 8 & 6.0 \\
\hline Graasten 5 & 19/03/17 & Urban & $4.2 / 1.5$ & 600 & 10.3 & 11.6 & 0.9 & 1 & 9.2 \\
\hline Graasten 6 & 20/03/17 & Urban & $4.2 / 1.5$ & 600 & 11.5 & 10.1 & 1.1 & 1 & 11.1 \\
\hline Aabenraa 1 & $10 / 04 / 13$ & Industry & $23.1 / 5.8$ & 900 & 12.6 & 70 & 0.2 & 3 & 2.6 \\
\hline Aabenraa 2 & $14-15 / 09 / 13$ & Industry & $23.1 / 5.8$ & 900 & 12.6 & 18.3 & 0.7 & 2 & 18.6 \\
\hline Padborg 1 & $04-05 / 11 / 12$ & Road/P & $15.5 / 10.1$ & 1400 & 9.8 & 12.3 & 0.8 & 1 & 1.8 \\
\hline Padborg 2 & $09-10 / 11 / 13$ & Road/P & $15.5 / 10.1$ & 1400 & 24.4 & 35 & 0.7 & 2 & 3 \\
\hline Padborg 3 & $11-14 / 11 / 13$ & Road/P & $15.5 / 10.1$ & 1400 & 6 & 52 & 0.1 & 2 & 24.4 \\
\hline Padborg 4 & $29-30 / 11 / 13$ & Road/P & $15.5 / 10.1$ & 1400 & 12.8 & 18 & 0.7 & 2 & 1.4 \\
\hline
\end{tabular}

During all events, flow SS, DP and PP were measured. In Padborg and Aabenraa, the water level in the inlets was measured by Onset Compute HOBO U20 water level loggers, with a temporal resolution of $5 \mathrm{~min}$. The water level was converted to flow by the Manning equation for not-full running pipes, and these flows were verified by manual flow measurements with a Kleinflügel Ott propeller Instrument. In Graasten, the flow was measured by an optic automatic flow recorder every minute. All water samples were sampled by a Teledyne ISCO model 6712 Portable Automatic Sampler. The water samples were taken with varying frequency. Before the rain event started, the frequency was $1-3 \mathrm{~h}$ depending on the station, and occasion, whereas during the first part of the event, the frequency was typically 15, 30 or $60 \mathrm{~min}$, and then an hour frequency in the last part of the event and after the event. Known volumes of all water samples were filtered in duplicate on pre-washed and pre-dried Whatman GF/C filters. DP was measured on the filtrate by the molybdenum-blue method [14]. The filters were dried for $24 \mathrm{~h}$ at $105^{\circ} \mathrm{C}$, or until constant weight, and the dry weight and filtered volume were used to calculate SS. After the ignition of the filters $\left(520^{\circ} \mathrm{C}, 5 \mathrm{~h}\right) \mathrm{PP}$ was measured by boiling the combusted filters in $1 \mathrm{M} \mathrm{HCl}(1 \mathrm{~h})$, followed by the determination of the DP in the extract [15]. 
Sigmaplot 12.0 was used for statistical analyses. $p<0.05$ was chosen as the level of significance, and linear regressions were performed after a normality test (Shapiro-Wilk) and constant variance.

\section{Results}

All 12 rain events were examined before, during and after the precipitation. Figure 2 presents the Aabenraa 2 rain event as an example. The flow regime follows the precipitation patterns, with an immediate increase in runoff when it starts raining and, simultaneously, a rapid decrease in the runoff when the rain stops. In this example, the concentrations of SS, DP and PP start to increase before the runoff, which indicates that the first water of this event contains a proportionally higher content of substances. Later in the event, the concentrations follow the flow patterns to a higher extent. The concentrations of SS, PP and DP declined rapidly when the rain stopped and the flow decreased. These tendencies were general for all 12 events. In the Aabenraa 2 case, the concentration of DP is higher than PP in the beginning of the event, and more equal in the later part of the event, but this varied between events.

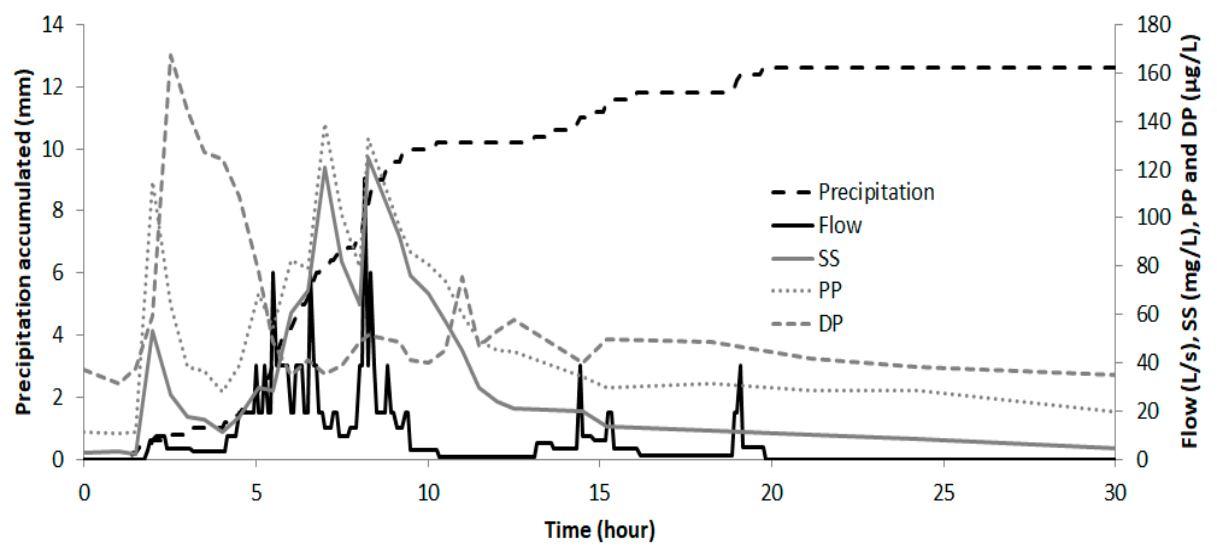

Figure 2. Aabenraa 2 as an example showing precipitation (primary y-axis), flow, and concentration of $\mathrm{PP}$ and DP (secondary y-axis) over time during the rain event.

Table 2 presents an overview of volumes and masses during the examined events. The total water volumes and masses for the specific events vary based on the catchment size and characteristics of the precipitation. In Graasten, the total volume per event ranged from 6-125 $\mathrm{m}^{3}$, whereas the corresponding volumes varied from $659-702 \mathrm{~m}^{3}$ in Aabenraa and $606-2424 \mathrm{~m}^{3}$ in Padborg. The total mass transport during the events varied according to the volumes. Regarding SS, 0.4-7 kg was discharged in Graasten, 44-90 kg in Aabenraa and 6-157 kg in Padborg. The corresponding discharge amounts for DP and PP were 1-39 and 2-18 g, respectively, for Graasten, 37-42 and 56-159 g for Aabenraa, and 85-408 and 25-260 g in Padborg.

In Figure 3, the L'/V' curves are given for all 12 events, and Table 2 shows the accumulated mass transport of SS, DP and PP at 20 and 30\% of the volume. Overall, there are clear first flush tendencies for some of the events, but there are also some without any tendency, and it varies among SS and DP/PP. Concerning SS, $>20 \%$ of the mass was transported with the first $20 \%$ of the water in half of the events (two in Graasten (26-27\%), one in Aabenraa (30\%), and three in Padborg (23-28\%)). The picture was similar at $30 \%$ of the volume with $32-64 \%$ of SS transported (Table 2, Figure 3). Also, DP and PP were showing first flush tendencies in some of the events, where $>20 \%$ DP mass was transported with the first $20 \%$ of the water in half of the events (three in Graasten (28-31\%), two in Aabenraa (33-34\%), and one in Padborg (23\%)), and five events had DP mass $>30 \%$ at $30 \%$ of the volume corresponding to $34-52 \%$ of the DP mass. Finally, $>20 \%$ of the PP mass was transported with the first $20 \%$ of the water in four of the events (two in Graasten (30-38\%), one in Aabenraa (24\%), and one in Padborg $(24 \%)$ ), whereas five events had PP mass $>30 \%$ at $30 \%$ of the volume equal to $34-44 \%$ of the PP mass. Both Padborg and Aabenraa expressed first flush tendencies in most cases, whereas the Graasten 
events varied between events with very clear first flush tendencies towards events completely without tendencies (Figure 3). Finally, there are also differences in the $\mathrm{L}^{\prime} / \mathrm{V}^{\prime}$ curves. Some are above the 45 degrees bisector during the whole event, whereas others are only above it during part of the event, indicating that a lower percentage than the corresponding volume of water is transported.

Table 2. Total discharged volume of water and mass transport of SS, DP and PP during the 12 events. Also, the percentage (\%) of SS, DP and PP discharged at 20 and 30\% discharged volume, respectively, is given. $\mathrm{G}=$ Graasten, $\mathrm{A}=$ Aabenraa and $\mathrm{P}=$ Padborg. Values in bold indicate that a larger fraction of substances have been discharged relative to the discharged volume.

\begin{tabular}{ccccccccccccc}
\hline Location & G1 & G2 & G3 & G4 & G5 & G6 & A1 & A2 & P1 & P2 & P3 & P4 \\
\hline Total volume $\left(\mathrm{m}^{3}\right)$ & 29 & 125 & 6 & 31 & 29 & 25 & 702 & 659 & 1103 & 2414 & 606 & 1242 \\
Total mass SS $(\mathrm{kg})$ & 3 & 7 & 0.4 & 3 & 1 & 1 & 44 & 90 & 6 & 82 & 25 & 157 \\
Total mass DP $(\mathrm{g})$ & 1 & 39 & 0.2 & 1 & 1 & 2 & 37 & 42 & 100 & 205 & 85 & 408 \\
Total mass PP (g) & 6 & 18 & 0.8 & 6 & 2 & 3 & 56 & 159 & 25 & 260 & 63 & 177 \\
\%SS at 20\% Vol & 19 & $\mathbf{2 6}$ & $\mathbf{2 7}$ & 12 & 6 & 20 & $\mathbf{3 0}$ & 9 & $\mathbf{2 6}$ & $\mathbf{2 8}$ & 8 & $\mathbf{2 3}$ \\
\%SS at 30\% Vol & 27 & $\mathbf{3 2}$ & $\mathbf{3 5}$ & 15 & 9 & 30 & $\mathbf{3 7}$ & 17 & $\mathbf{6 4}$ & $\mathbf{3 6}$ & 16 & $\mathbf{3 8}$ \\
\%DP at 20\% Vol & $\mathbf{3 1}$ & 17 & $\mathbf{2 8}$ & 17 & 7 & $\mathbf{3 0}$ & $\mathbf{3 3}$ & $\mathbf{3 4}$ & 11 & 20 & 8 & $\mathbf{2 3}$ \\
\%DP at 30\% Vol & $\mathbf{4 4}$ & 26 & $\mathbf{3 6}$ & 30 & 9 & 30 & $\mathbf{5 2}$ & $\mathbf{4 2}$ & 21 & 29 & 14 & $\mathbf{3 4}$ \\
\%PP at 20\% Vol & 19 & $\mathbf{3 0}$ & $\mathbf{3 8}$ & 17 & 16 & 20 & $\mathbf{2 4}$ & 15 & $\mathbf{2 4}$ & 21 & 11 & 15 \\
\%PP at 30\% Vol & 27 & $\mathbf{3 8}$ & $\mathbf{4 4}$ & 25 & 23 & 29 & $\mathbf{3 4}$ & 24 & $\mathbf{4 4}$ & $\mathbf{3 4}$ & 23 & 30 \\
\hline
\end{tabular}
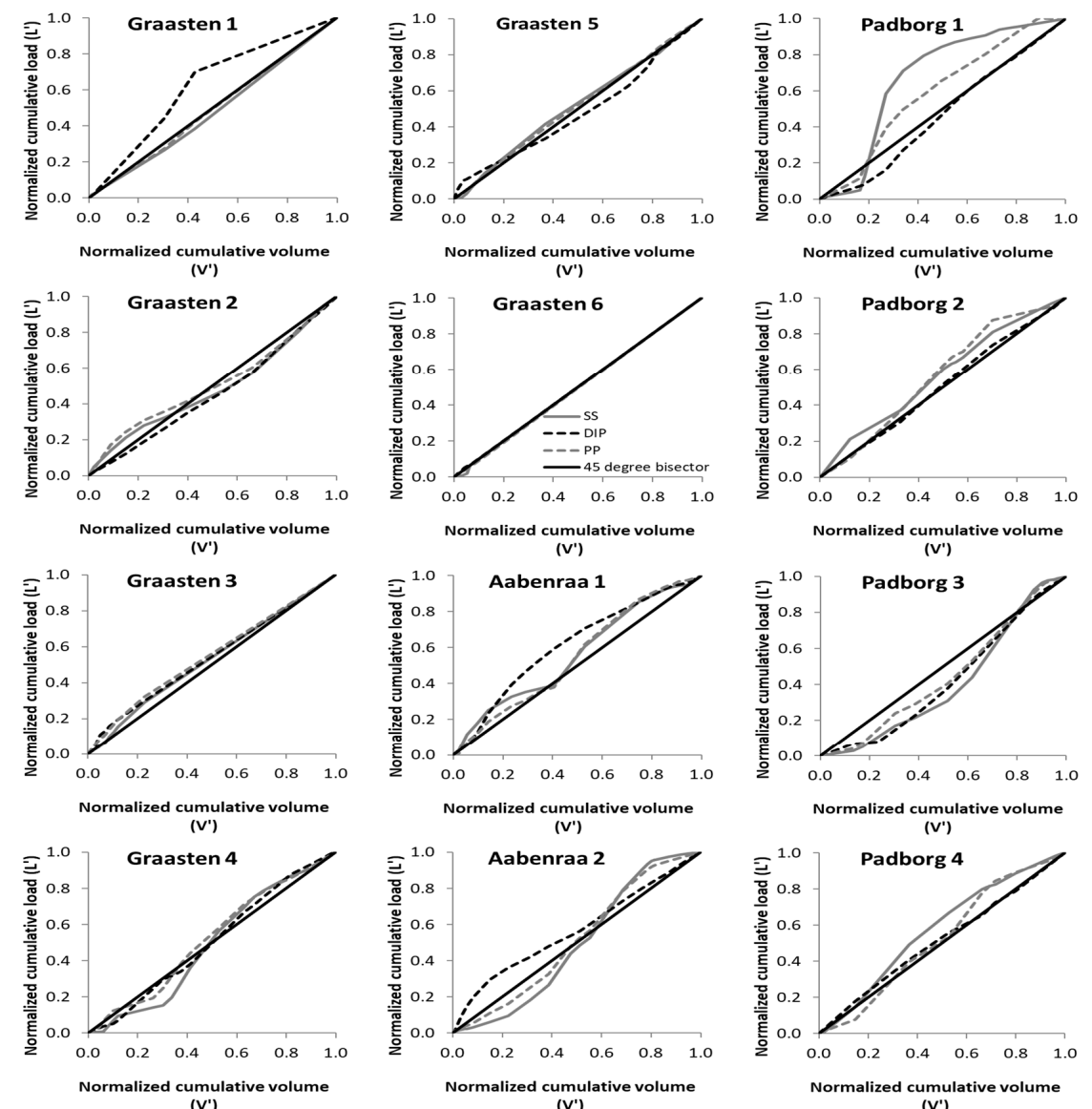

Figure 3. $L^{\prime} / V^{\prime}$ curves for the 12 events. $L^{\prime}$ is the mass load and $V^{\prime}$ is the volume, with both expressed as normalized accumulated values.

A regression analysis performed on all the studied parameters described above revealed several significant correlations (Figure 4a-i, Table 3). There was a significant positive correlation between the total discharged mass of total SS and PP versus the total catchment area (Figure $4 \mathrm{a}, p=0.027$ 
for both). The same was the case for SS $(p=0.028), \operatorname{PP}(p=0.012)$ and DP $(p=0.007)$ versus the reduced catchment area (Figure $4 \mathrm{~b}$ ). The longer the maximum distance in the catchment, the more SS and P were transported and discharged. That was also significance for total SS $(p=0.039)$, total PP $(p=0.017)$ and total DP $(p=0.005)$ (Figure 4c). Knowledge about event characteristics can also give information about expected discharge of SS and P (Figure $4 \mathrm{~d}-\mathrm{f}$ ), as we found a significant positive correlation for total discharged PP versus total precipitation during the event $(p=0.030)$, a significant positive correlation for $\%$ total discharged PP at $20 \%$ of the volume versus the rain intensity $(p=0.017)$ and a negative correlation for the corresponding SS \% at $20 \%$ volume versus the amount of precipitation during the previous rain event $(p=0.035)$. Finally, significant correlations among the measured parameters were found (Figure 4g-i). Total discharged SS, PP and DP correlated positively and significantly with the total discharged volume ( $p=0.021,<0.001$ and 0.010 , respectively). Among SS and P, there was a positive and significant relationship between the total discharged amounts of PP and DP versus SS $(p<0.001$ for both), and total DP versus total PP $(p=0.007)$.
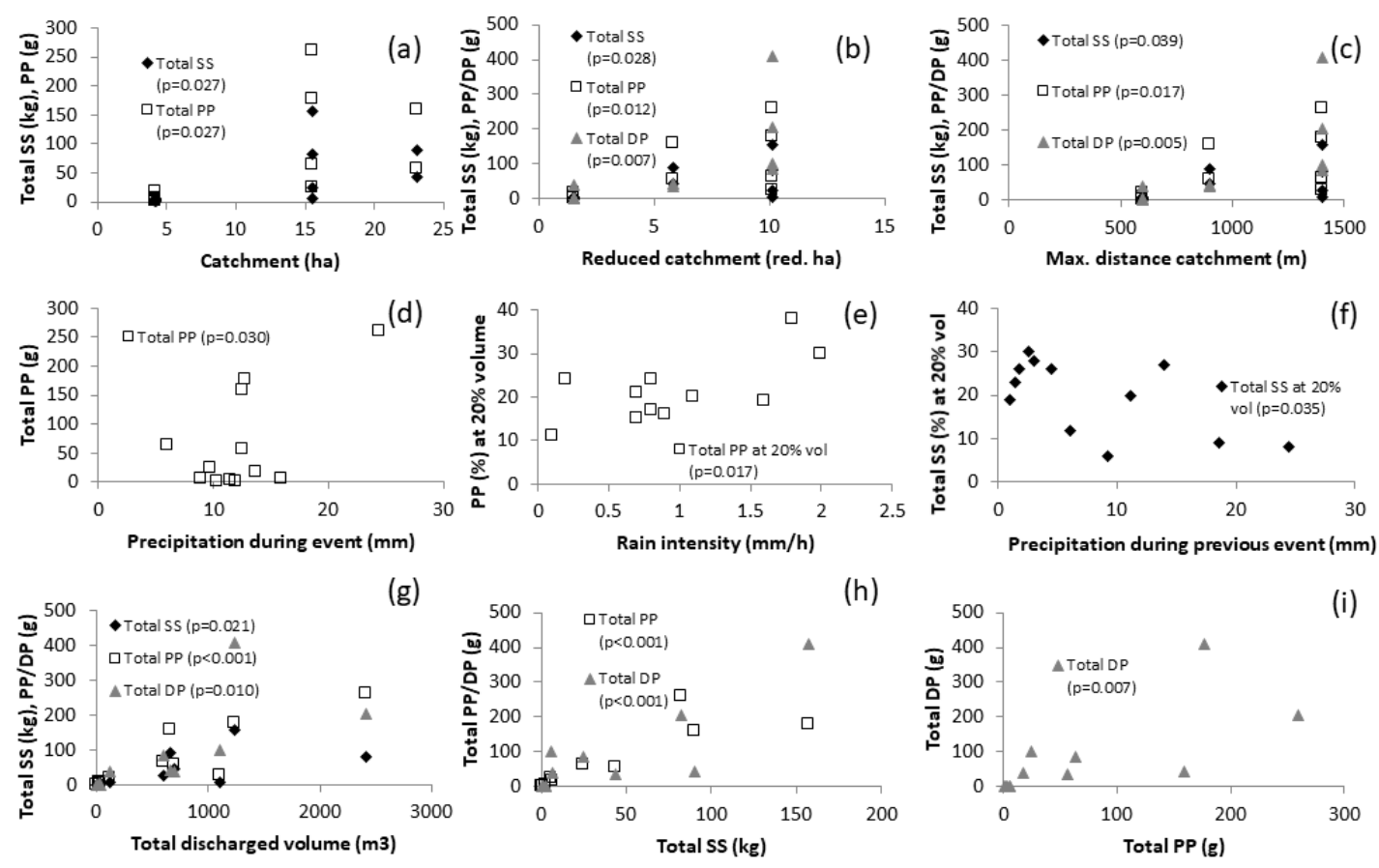

Figure 4. Significant correlations between the studied parameters, including data from all measured events $(\mathbf{a}-\mathbf{i}) \cdot \mathrm{n}=12$.

Table 3. Regression parameters $\left(\mathrm{r}_{\text {and }} \mathrm{r}^{2}\right.$ ) concerning the significant correlations presented in Figure $4 \mathrm{a}-\mathrm{i}$ (values in bold), plus the coefficients for the nonsignificant correlations. $N=12$. (-) not relevant.

\begin{tabular}{|c|c|c|c|c|c|c|c|c|c|}
\hline Figure & $4 a$ & $4 b$ & $4 c$ & $4 d$ & $4 e$ & $4 \mathrm{f}$ & $4 g$ & $4 \mathrm{~h}$ & $4 \mathrm{i}$ \\
\hline & \multicolumn{9}{|c|}{$\mathrm{r} / \mathrm{r}^{2}$} \\
\hline \multirow{2}{*}{ Total SS } & $0.63 /$ & $0.63 /$ & $0.60 /$ & $0.34 /$ & \multirow[t]{2}{*}{ - } & $0.61 /$ & $0.65 /$ & \multirow[t]{2}{*}{ - } & \multirow[t]{2}{*}{-} \\
\hline & 0.40 & 0.40 & 0.36 & 0.12 & & 0.37 & 0.43 & & \\
\hline Total & $0.41 /$ & $0.73 /$ & $0.75 /$ & $0.29 /$ & \multirow[b]{2}{*}{ - } & \multirow{2}{*}{ - } & $0.71 /$ & $0.86 /$ & $0.73 /$ \\
\hline DP & 0.17 & 0.53 & 0.56 & 0.09 & & & 0.51 & 0.74 & 0.53 \\
\hline \multirow{2}{*}{ Total PP } & $0.63 /$ & $0.69 /$ & $0.67 /$ & $0.62 /$ & $0.67 /$ & \multirow[t]{2}{*}{ - } & $0.88 /$ & $0.86 /$ & \multirow{2}{*}{ - } \\
\hline & 0.40 & 0.48 & 0.45 & 0.39 & 0.45 & & 0.77 & 0.73 & \\
\hline
\end{tabular}

\section{Discussion}

This study does not include intense rain events, where first flush most likely occurs, but only regular smaller rain events, which covers nearly $90 \%$ of all rain events in the study area [12]. Even so, the study still demonstrates that the amount, intensity and pollution patterns of stormwater discharge 
varies both during a single precipitation event and among different events, as the dynamic of the discharged stormwater can be dependent on many parameters. This study also clearly demonstrated that the 12 studied events do not express either a 20/80 or a 30/80 first flush pattern, but we still see first flush tendencies close to the 20/40 and 25/50 scenarios. This is most likely due to the relatively small catchment areas, as first flush is a phenomenon most often seen in smaller catchments [11], and in this study the reduced catchments are below 10.1 ha. Therefore, it is beneficial to ensure treatment of the first part of a rain event, e.g., if the available area for stormwater pond establishment is restricted. Finally, this study finds very clear and significant relationships between catchment characteristics, precipitation characteristics and the quality of the discharged stormwater.

In all events, the runoff starts immediately after the onset of precipitation, due to the limited retention possibilities in the paved areas. It is also characteristic that the SS and P concentrations peak before the flow peak indicating first flush, as the first stormwater that is discharged has flushed the paved surfaces for substances accumulated since the last rain event, as seen in other studies [16,17]. The total discharged volume, SS and P were naturally dependent on catchment size and maximum pipe distance in the catchment, as a larger area accumulates a larger amount of both water and substances. The ratio between PP and DP is often stated to be 50:50 [16], which is also the case in many of the studied events. However, some of the Graasten and Padborg events had a higher proportion of DP, which is problematic, as the methods used to treat stormwater very often rely on sedimentation processes [6], which are only effective for PP. On the other hand, the events from Aabenraa had a higher proportion of PP. Methods that remove DP effectively from the stormwater, and are at the same time easy to manage and cost-effective, are still lacking. Constructed wetlands with a high nutrient uptake/cycling due to biomass production, followed by biomass removal could be an option. Part of the DP measured in Graasten and Padborg might be particulates bound to small particles/colloids, that have passed the filter used for separating the two fractions, but if that is the case, these small particles are still very difficult to retain in, for example, sedimentation ponds, as the required retention time is long. The significant relationships between SS and DP/PP, as well as PP and DP, are indicate that a fraction of DP might be either particulate bound or loosely adsorbed $\mathrm{P}$.

The $\mathrm{L}^{\prime} / \mathrm{V}^{\prime}$ curves show a first flush tendency for $50 \%$ of the events concerning both SS and P. The initial discharged mass is though not to be high enough to fulfill the 30/80 or 20/80 requirement suggested by other studies [7,10,11]. Our findings are closer to the 20/40 suggestion [9]. A reason for why we are not seeing a more pronounced first flush tendency is probably that all our investigated rain events are rather small; on average $12.6 \mathrm{~mm}$. More intense events are of course expected to give clearer first flush tendencies, but we decided to study the smaller and more common event sizes, as the events $<10 \mathrm{~mm}$ in the studied area cover $86 \%$ of the early precipitation patterns [12], and this majority of events also carry the largest part of the discharged mass. Other reasons for why we do not always see first flush tendencies, as also seen in this study, could be: (1) recent rain events had cleaned the surfaces, and therefore no new accumulation of material occurred; (2) calm rain intensities removed material from the surfaces over a longer period of the event; and (3) stormwater retention mechanisms in the catchments slowed down the discharge velocity.

It was primarily the particulate fractions (SS and PP) that were dependent on the rain characteristics (amount, intensity and previous rain amount), because these substances accumulate and stay on the surfaces to a larger extent than the dissolved fractions. The significant negative relationship between rain depth and the discharged amount of PP during the first $20 \%$ of the volume, and the number of days since last event and the discharged amount of SS during the first $20 \%$ of the volume, clearly expresses how important the rain history is for determining first flush. The partial importance of rain depth and intensity was found in [18], where these two factors were the first and second most important variable for first flush. We have only studied SS and P, but it would be highly relevant to perform a similar study for metals, as performed by others [19]. This is important, as many metals are bound just as often to particles as $\mathrm{P}$ [20]. The treatment of $\mathrm{P}$, metals and other xenobiotics in discharged stormwater can be improved if event characteristics, like those reported in this paper, can be used to target the treatment 
methods towards the volume of water with the highest mass content. It is, however, often difficult to obtain samples from full rain events, like those in this study, as it should either be done manually with a good prediction of when the rain starts, not to lose the initial part of the event, or have automatic sample equipment coupled to information from a rain gauge. Therefore, many stormwater samples are instead either point samples or flow-weighted average samples, which do not give the kind of information needed to study first flush characteristics. We have studied 12 whole events, and they are representative for Danish conditions and many other northern European catchments, and even though there might be local difference, we have a solid basis for the conclusions below.

\section{Conclusions}

In conclusion, the 12 studied events clearly demonstrate that:

- In approximately 50\% of the events, a larger part of SS and P was transported and discharged in the first part of the event, indicating a first flush tendency.

- The transport of particulate matter and particulate $\mathrm{P}$ is significantly dependent on catchment characteristics, but also on rain amount, rain intensity and rain during the previous event. These findings are important for management and treatment of stormwater before discharge.

- First flush discharge can be minimized by designing wet ponds with the overflow facility at the inlet instead of the outlet, to ensure the treatment of the first flush volume in the pond.

- A considerable part of the P content is DP, which can't be handled through traditional sedimentation methods, but can be removed, for example, by uptake in biomass or biofilm in properly designed ponds with a sufficiently long retention time.

Therefore, we suggest that future treatment systems should be designed to ensure the treatment of the first part of the rain event, in order to optimize both retention efficiencies and the cost-effectiveness of the pond.

Author Contributions: Conceptualization, S.E., M.J.S. and M.R.F.; methodology, S.E., A.B.P., M.J.S. and M.R.F.; software, S.E., A.B.P., and M.J.S.; validation, S.E., A.B.P., M.J.S. and M.R.F.; formal analysis, A.B.P. and M.J.S.; investigation, A.B.P. and M.J.S.; resources, S.E. and M.R.F.; data curation, S.E., A.B.P., M.J.S. and M.R.F.; writing - original draft preparation, S.E.; writing — review and editing, S.E., A.B.P., M.J.S. and M.R.F.; visualization, S.E. and A.B.P.; supervision, S.E. and M.R.F.; project administration, S.E. and M.R.F; funding acquisition, S.E. and M.R.F. All authors have read and agreed to the published version of the manuscript.

Funding: The study was supported by two industrial PhD projects granted by the Danish Ministry of Science, Innovation and Higher Education, FI case number 11-109519 and 5016-00136B.

Acknowledgments: Thanks to Sønderborg Utility Company, Arwos A/S and Ramboll A/S for cooperation and access to stormwater systems, wet ponds and background data. Thanks to the Ecology Laboratory at the University of Sothern Denmark for assistance with samples, and thanks to the former masters students for their contributions.

Conflicts of Interest: The authors declare no conflict of interest. The funders had no role in the design of the study; in the collection, analysis, or interpretation of data; in the writing of the manuscript, or in the decision to publish the results.

\section{References}

1. Cubash, U.; Wuebbles, D.; Chen, D.; Facchini, M.C.; Frame, D.; Mahowald, N.; Winther, J.G. Introduction in Climate Change 2013: The Physical Science Basis. Contribution of Working Group I to the Fifth Assesment Report of the Intergovernmental Panel on Climate Change; Cambridge University Press: Cambridge, UK; New York, NY, USA, 2013.

2. IPCC. Climate Change 2014: Synthesis Report. Contribution of Working Groups I, II and III to the Fifth Assessment Report of the Intergovernmental Panel on Climate Change; Pachauri, R.K., Meyer, L.A., Eds.; IPCC: Geneva, Switzerland, 2014.

3. Drews, M.; Boberg, F.; Cappelen, J.; Christensen, O.B.; Lundhold, S.C.; Olesen, M. Future Precipitation Changes in Denmark; Danish Climate Center Report; Danish Meteorological Institute: Copenhagen, Denmark, 2011.

4. Danva. A Manual to Analyze the Effects of Climate Changes in the Urban Flooding's; Danva Report; Danva: Skanderborg, Denmark, 2011. 
5. Hvitved-Jacobsen, T.; Vollertsen, J.; Nielsen, A.H. Urban and Highway Stormwater Pollution: Concepts and Engineering; CRC/Taylor and Francis: Boca Raton, FL, USA, 2010.

6. Barbosa, A.E.; Hvitved-Jacobsen, T. Infiltration pond design for highway runoff treatment in semiarid climates. J. Environ. Eng. 2001, 127, 1014-1022. [CrossRef]

7. Sansalone, J.J.; Cristina, C.M. First flush concepts for suspended and dissolved solids in small impervious watersheds. J. Environ. Eng. 2004, 130, 1301-1314. [CrossRef]

8. Arias, M.E.; Brown, M.T.; Sansalone, J.J. Characterization of Storm Water-Suspended Sediments and Phosphorus in an Urban Catchment in Florida. J. Environ. Eng. 2013, 139, 277-288. [CrossRef]

9. Hathaway, J.M.; Tucker, R.S.; Spooner, J.M.; Hunt, W.F. A Traditional Analysis of the First Flush Effect for Nutrients in Stormwater Runoff from Two Small Urban Catchments. Water Air Soil Pollut. 2012, 223, 5903-5915. [CrossRef]

10. Bertrand-Krajewski, J.L.; Chebbo, G.; Saget, A. Distribution of pollutant mass vs volume in stormwater discharges and the first flush phenomenon. Water Res. 1998, 32, 2341-2356. [CrossRef]

11. Mamun, A.A.; Shams, S.; Nuruzzaman, M. Review on uncertainty of the first-flush phenomenon in diffuse pollution control. Appl. Water Sci. 2020, 10, 53. [CrossRef]

12. Sønderup, M.J.; Egemose, S.; Hansen, A.S.; Grudinina, A.; Madsen, M.H.; Flindt, M.R. Factors affecting retention of nutrients and organic matter in stormwater ponds. Ecohydrology 2016, 9, 796-806. [CrossRef]

13. Mallin, M.A.; Ensign, S.H.; Wheeler, T.L.; Mayes, D.B. Pollutant removal efficacy of three wet detention ponds. J. Environ. Qual. 2002, 31, 654-660. [CrossRef] [PubMed]

14. Koroleff, F. Determination of phosphorus. In Methods of Seawater Analysis, 2nd ed.; Grasshoff, K., Erhardt, M., Kremling, K., Eds.; Verlag Chemie: Weinheim, Germany, 1983; pp. 125-139.

15. Andersen, J.M. An ignition method for determination of total phosphorus in lake sediments. Water Res. 1976, 10, 329-331. [CrossRef]

16. Egemose, S.; Jensen, H.S. Phosphorus forms in urban and agricultural runoff: Implications for management of Danish Lake Nordborg. Lake Reserv. Manag. 2009, 25, 410-418. [CrossRef]

17. Sønderup, M.J.; Egemose, S.; Bochdam, T.; Flindt, M.R. Treatment efficiency of a wet detention pond combined with filters of crushed concrete and sand: A Danish full-scale study of stormwater. Environ. Monit. Assess. 2015, 187, 758. [CrossRef] [PubMed]

18. Perera, T.; McGree, J.; Egodawatta, P.; Jinadasa, K.B.S.N.; Goonetilleke, A. Taxonomy of influencial factors for predicting pollutant first flush in urban stormwater runoff. Water Res. 2019, 166, 115075. [CrossRef] [PubMed]

19. Sansalone, J.J.; Buchberger, S.G. Partitioning and first flush of metals in urban roadway storm water. J. Environ. Eng. 1997, 123, 134-143. [CrossRef]

20. Egemose, S.; Sønderup, M.J.; Grudinina, A.; Hansen, A.S.; Flindt, M. Heavy metal composition in stormwater, and retention in ponds depending on pond age, design and catchment type. Environ. Technol. 2015, 36, 959-969. [CrossRef] [PubMed]

(C) 2020 by the authors. Licensee MDPI, Basel, Switzerland. This article is an open access article distributed under the terms and conditions of the Creative Commons Attribution (CC BY) license (http://creativecommons.org/licenses/by/4.0/). 